\title{
Political Announcements and Exchange Rate Expectations
}

\author{
BrigitTa Tóth-BozÓa ${ }^{\mathrm{a}} \quad$ LÁszló SzAlAI \\ Received: 06.08.2019; Revised: 27.10.2019; Accepted: 7.11.2019
}

\begin{abstract}
Exchange rate fluctuations in a small open economy are closely related to political trust. Various political announcements exert significant influence on the exchange rate by affecting the expectations of economic actors. Due to information technology and social networks, these statements spread quicker and gain more publicity than ever before. In this paper, we present a dynamic model with adaptive expectations to describe the short and long-run effects of political announcements on the exchange rate. We found that relevant announcements cause significant fluctuations in the short-run but do not affect the long-term equilibrium exchange rate. Our results are also supported by case-studies from Hungary.
\end{abstract}

JEL codes: C61, C62, D84, F31

Keywords: Dynamic model; Political announcements; Exchange rate; Adaptive expectations

\section{Overview}

The classic literature concerning the relationship between political and economic expectations dates back to the middle of the past century (Mundell, 1963; Mussa, 1976; Samuelson, 1964). In particular, there are studies describing how political announcements affect different socioeconomic indicators. Frenkel (1982) argued that news - as information about the political, social, and economic events in a country - are key factors in the determination of the currency exchange rate. Cosset \& de la Rianderie (1985) examined the effects of news from the Wall Street Journal that involved information on political risks. They reported a significant influence on the investors and found that exchange rate dynamics were strongly related to the announcements. Moreover, this relation is more expressed in the case of bad news. That is, the given currency depreciates more after negative events than it appreciates following the release of positive statements. Political news also affects the forward bias and partially explain why short-term exchange rates differ from predictions based on interest rate parity models (Bachman, 1992). Similarly, Blomberg \& Hess (1997) showed that introducing political variables to exchange rate models improves forecasting significantly in comparison to the random walk models. A very recent empirical study by Sohu et al. (2019) concluded that the perception of corruption was related to the depreciation of the currencies of India and Pakistan.

${ }^{a}$ Budapest University of Technology and Economics, Budapest, Hungary. e-mail: bbrigitta@kgt.bme.hu

b Corresponding author. Budapest University of Technology and Economics, Budapest, Hungary. e-mail: szalai@kgt.bme.hu 
Kaiser (1997) investigated the impact of news on social expectations as Germany was joining the European Monetary Union. He concluded that in case of negative news people found it less likely that the country will be a member by the deadline set and pointed out that expectations are very sensitive in terms of political news and events. In accordance, Niederhoffer (1971) found a significant effect of world events on stock market prices. Based on the analysis of New York Times headlines, he also argues that markets tend to overreact bad news and random walk models might be improved by counting for the effects of announcements on expectations. The linkage also works the other way; as Hetherington (1998) showed, political confidence is highly dependent on economic variables and other measures of government effectiveness.

Besides other fundamental economic determinants, the demand and supply of a given currency -and so the equilibrium exchange rate- is affected by the expectations of both domestic and foreign investors. In turn, their expectations are largely dependent on news and political statements since they carry essential information on the economic outlook of the possible investment targets. In this paper, we distinguish between positive and negative announcements in terms of how they affect the expectations. The positive news is assumed to foster expectations concerning the appreciation of the currency (a lower exchange rate) while negative news acts the opposite way and drive expectations towards depreciation (a higher exchange rate).

In the following section, we develop a theoretical model to show how exogenous political announcements affect expectations and the equilibrium exchange rate on different time horizons. We would like to provide a better insight into the relation of foreign exchange market dynamics and political statements that do not include new information on economic fundamentals. To achieve that, we strongly rely on an earlier model published by Dornbusch (1976). However, we will implement discrete variables to control better for periodically published economic indicators, and we also change the concept of expectations from rational to adaptive to resemble a learning process. The original model describes how monetary policy affects exchange rates and concludes that expansion causes the currency to depreciate. Moreover, Dornbusch showed that an initial overshooting on the exchange rate arises due to the slower adjustment speed of the commodity markets. In this paper, we adopt his framework to investigate the overshooting and the long-run equilibrium after positive and negative political announcements.

In the following two sections, we develop the model and analyze the stability of the steady-state solution, respectively. In Sections 4 and 5, we introduce political announcements first as exogenous and later as endogenous variables. Section 6 contains two short but illustrative case studies from Hungary, while Section 7 summarizes the conclusions derived from the model. For the convenience of the reader, we only discuss the model parameters shortly in the text, but we provide a summary of them in the Appendix.

\section{Model}

Consider a small open economy with perfect capital mobility and exogenous import prices. We focus on the exchange rate $(E)$, the expected exchange rate $\left(E^{e x p}\right)$ and the domestic price level $(P)$ as endogenous variables of the model. All other parameters, such as the national income $(Y)$, the money supply $(M)$, and the global interest rate $\left(R^{*}\right)$ are 
exogenous and assumed to grow with a constant rate in each period.

$$
\begin{aligned}
& R_{t}^{*}=(1+\Psi) R_{t-1}^{*}, \quad \Psi \in(-1,1) \\
& M_{t}=(1+T) M_{t-1}, \quad T \in(-1,1) \\
& Y_{t}=(1+H) Y_{t-1}, \quad H \in(-1,1)
\end{aligned}
$$

By setting the value of parameters $\Psi, T$, and $H$, the model might be configured for different international and country-specific conditions. In particular, a negative parameter resembles a decreasing trend in the related exogenous variable, positive parameters capture an increasing trend, whereas zero values represent a stable environment. For mathematical convenience and in accordance with the original model, we transform these equations to their logarithmic form:

$$
\begin{aligned}
r_{t}^{*} & =\varphi+r_{t-1}^{*}, \quad \varphi=\ln (1+\Psi) \\
m_{t} & =\tau+m_{t-1}, \quad \tau=\ln (1+T) \\
y_{t} & =\vartheta+y_{t-1}, \quad \vartheta=\ln (1+H)
\end{aligned}
$$

The domestic interest rate is assumed to be dependent on the global rate and a special factor that describes the appreciation or the depreciation of the currency:

$$
r_{t}=r_{t}^{*}+x_{t}
$$

where $x_{t}$ is defined as:

$$
x_{t}=e_{t}^{e x p}-e_{t-1}
$$

That is, the domestic interest rate is determined not just by the exchange rate of the previous period but also the expectations on its value in the current period. To introduce the learning process with adaptive expectations we define the expected exchange rate as:

$$
e_{t}^{e x p}=\beta e_{t-1}^{e x p}+(1-\beta) e_{t-1}, \quad \beta \in(0,1)
$$

The parameter $\beta$ defines the learning process and describes how economic actors refine their expectations over the time. Considering the money market, we assume a Cagan-type demand function expressed in a logarithmic formula:

$$
\begin{aligned}
\frac{M}{P} & =Y^{\phi}(\exp )^{-\lambda r} \\
-\lambda r_{t}+\phi y_{t} & =m_{t}-p_{t}, \quad \lambda \in(0,1)
\end{aligned}
$$

For simplicity, we suppose that the nominal supply of money is constant over time. As for the goods market, we implement discrete variables into the original concept of Dornbusch to describe domestic prices. The dynamics of the domestic price level are defined as:

$$
\begin{aligned}
\Delta p_{t}=p_{t}-p_{t-1}=\pi & \pi u+\delta\left(e_{t-1}-p_{t-1}\right)+ \\
& \left.(\gamma-1) y_{t-1}-\sigma r_{t-1}\right]
\end{aligned}
$$

where $\pi$ represents the speed of adjustment, $u$ is a shift parameter, $\delta$ controls for the effects of the difference between the price level and the exchange rate, $\gamma$ is a multiplicative parameter 
for the domestic income, and $\sigma$ describes the effects of changes in the global interest rate. Thus, the dynamics are determined by the exchange rate, the domestic interest rate, the nominal income, and the price level of the previous period. A decrease in the prices drives higher demand just as an increase in the national income or a decrease in the domestic interest rate. Since the money market is defined in a Keynesian tradition, the domestic interest rate has to fulfil the equilibrium criteria in every period. It follows, that:

$$
-\lambda r_{t-1}+\phi y_{t-1}=m_{t-1}-p_{t-1}
$$

After minor transformations we obtain:

$$
r_{t-1}=\frac{-1}{\lambda} m_{t-1}+\frac{1}{\lambda} p_{t-1}+\frac{\phi}{\lambda} y_{t-1}
$$

By reordering and substituting (14) into (12) we have

$$
\begin{gathered}
p_{t}=\left(1-\pi \delta-\frac{\sigma}{\lambda}\right) p_{t-1}+\pi \delta e_{t-1}+ \\
\left(\gamma-1-\frac{\varphi}{\lambda}\right) y_{t-1}+\frac{\sigma}{\lambda} m_{t-1}+\pi u
\end{gathered}
$$

to describe the current price level. Please note that our concept of the exchange rate differs from the original Dornbusch model as we assume a flexible foreign exchange market where the equilibrium exchange rate is determined by the international demand and supply. The exchange rate dynamics are given by:

$$
\Delta e_{t}=e_{t}-e_{t-1}=\mu\left(D_{t}^{D}-D_{t}^{S}\right), \quad \mu \in(0,1)
$$

where $D^{D}$ and $D^{S}$ stand for the demand and the supply of the foreign currency, respectively, which are closely related to foreign trade. The demand is driven by imports whereas the supply is driven by exports. Therefore, we define the demand function according to the exchange rate and the domestic income, while supply is determined by the exchange rate and the foreign income:

$$
\begin{gathered}
D_{t}^{D}=f\left(e_{t}, y_{t}\right)=-\kappa e_{t}+\zeta y_{t} \\
D_{t}^{S}=g\left(e_{t}, y^{*}\right)=\omega e_{t}+\xi y^{*}
\end{gathered}
$$

where $\kappa, \zeta, \omega$, and $\xi$ are positive parameters. By substituting these functions into equation (16) we obtain:

$$
\Delta e_{t}=e_{t}-e_{t-1}=\mu\left(-\kappa e_{t}+\zeta y_{t}-\omega e_{t}-\xi y^{*}\right)
$$

The equation governing the exchange rate follows directly after a rearrangement:

$$
e_{t}=\frac{\mu}{1+\mu(\kappa+\omega)}\left[\zeta y_{t}-\xi y^{*}\right]+\frac{1}{1+\mu(\kappa+\omega)} e_{t-1}
$$

Thus, the current spot exchange rate depends on the domestic income, on the foreign income, and on the exchange rate of previous period. For simplicity, we assume that the foreign income is constant over time. Our model might be summarized with the following equations: 
(i) The domestic interest rate:

$$
r_{t}=r_{t}^{*}+x_{t}
$$

(ii) The rate of appreciation or depreciation:

$$
x_{t}=e_{t}^{e x p}-e_{t-1}
$$

(iii) The equation for adaptive expectations:

$$
e_{t}^{e x p}=\beta e_{t-1}^{e x p}+(1-\beta) e_{t-1}
$$

(iv) The exchange rate dynamics:

$$
e_{t}=\frac{\mu}{1+\mu(\kappa+\omega)}\left[\zeta y_{t}-\xi y^{*}\right]+\frac{1}{1+\mu(\kappa+\omega)} e_{t-1}
$$

(v) The price level dynamics:

$$
\begin{aligned}
p_{t}=\left(1-\pi \delta-\frac{\sigma}{\lambda}\right) p_{t-1}+\pi \delta e_{t-1}+ \\
\left(\gamma-1-\frac{\varphi}{\lambda}\right) y_{t-1}+\frac{\sigma}{\lambda} m_{t-1}+\pi u
\end{aligned}
$$

(vi) The money market equilibrium:

$$
-\lambda r_{t}+\phi y_{t}=m_{t}-p_{t}
$$

The model might be expressed in a matrix-form as well. Using equations (21-26), the intertemporal interdependence among the endogenous variables is described by the following system of difference equations:

$$
\begin{aligned}
{\left[\begin{array}{c}
e_{t}^{e x p} \\
e_{t} \\
p_{t}
\end{array}\right]=} & {\left[\begin{array}{ccc}
\beta & (1-\beta) & 0 \\
0 & \frac{1}{1+\mu(\kappa+\omega)} & 0 \\
0 & \mu \delta & 1-\pi \delta-\frac{\sigma}{\lambda}
\end{array}\right]\left[\begin{array}{c}
e_{t-1}^{e x p} \\
e_{t-1} \\
p_{t-1}
\end{array}\right]+} \\
& {\left[\begin{array}{c}
\frac{\mu}{1+\mu(\kappa+\omega)}\left[\zeta\left(y_{t-1}+\vartheta\right)-\xi y^{*}\right] \\
\left(\gamma-1-\frac{\varphi}{\lambda}\right) y_{t-1}+\frac{\sigma}{\lambda} m_{t-1}+\pi u
\end{array}\right] }
\end{aligned}
$$

In the next section, we present the equilibrium solution of the system, where the endogenous variables are constant over time, and the model is in a steady-state.

\section{Solution and Stability}

Formally, the model is in a steady-state equilibrium if

$$
\left[\begin{array}{c}
e_{t}^{e x p} \\
e_{t} \\
p_{t}
\end{array}\right]=\left[\begin{array}{l}
e_{t-1}^{e x p} \\
e_{t-1} \\
p_{t-1}
\end{array}\right]
$$


Following the general solution mechanism for difference equations by Galor (2004), from equation (27) we have

$$
\overline{\mathcal{E}}=[I-A]^{-1} \bar{B}
$$

where vector $\overline{\mathcal{E}}$ denotes the equilibrium of the system, and

$$
\begin{gathered}
A=\left[\begin{array}{ccc}
\beta & (1-\beta) & 0 \\
0 & \frac{1}{1+\mu(\kappa+\omega)} & 0 \\
0 & \mu \delta & 1-\pi \delta-\frac{\sigma}{\lambda}
\end{array}\right] \\
B=\left[\begin{array}{c}
0 \\
\frac{\mu}{1+\mu(\kappa+\omega)}\left[\zeta\left(y_{t-1}+\vartheta\right)-\xi y^{*}\right] \\
\left(\gamma-1-\frac{\varphi}{\lambda}\right) y_{t-1}+\frac{\sigma}{\lambda} m_{t-1}+\pi u
\end{array}\right]
\end{gathered}
$$

Therefore,

$$
\overline{\mathcal{E}}=\left[\begin{array}{c}
\frac{\left[\zeta\left(y_{t-1}+\vartheta\right)-\xi y^{*}\right]}{\mu(\kappa+\omega)} \\
\frac{\left[\zeta\left(y_{t-1}+\vartheta\right)-\xi y^{*}\right]}{\mu(\kappa+\omega)} \\
\frac{\left[\zeta\left(y_{t-1}+\vartheta\right)-\xi y^{*}\right] \pi \delta}{(\kappa+\omega)\left(\pi \delta+\frac{\sigma}{\lambda}\right)}+\left[\left(\gamma-1-\frac{\varphi}{\lambda}\right) y_{t-1}+\frac{\sigma}{\lambda} m_{t-1}+\pi u\right] \frac{1}{\left(\pi \delta+\frac{\sigma}{\lambda}\right)}
\end{array}\right]
$$

From (32), it follows that the actual and the expected exchange rates are equal in the long run since both of them are determined by processes on the foreign exchange market. More precisely, the equilibrium exchange rate reflects how domestic and foreign incomes drive international trade, and thus, the demand and supply of foreign currencies. The expected exchange rate converges to the long-run equilibrium as adaptive expectations are built into the model and economic actors undergo the learning process. Please note that expectations do not affect the long-term equilibrium and that parameter $\beta$ only governs the speed of adjustment.

Besides incomes and interest rate parameters $(\sigma, \varphi)$, the equilibrium price level also depends on the adjustment speed of the goods market $(\pi)$. Thus, the equilibrium arises as an interaction between all the discussed markets. However, in this paper, we keep our focus on the exchange rate. The steady-state may be calculated by any initial values, but it is only stable if

$$
\operatorname{det}|I-A| \neq 0 \text { and }\left|\tau_{i}<1\right| \text { for } i=1,2, \ldots, n
$$

where $\tau_{i}$ denotes the eigenvalues of the coefficient matrix (Galor, 2005). In our case this translates to

$$
\operatorname{det}|I-A|=(1-\beta) \mu(\kappa+\omega)\left(\pi \delta+\frac{\sigma}{\lambda}\right) \frac{1}{1+\mu(\kappa+\omega)}
$$

Let us have a closer look at the expressions in (34) to verify the stability criteria. First, $(1-\beta)$ equals zero only if $\beta=1$. That is, economic actors would expect the same exchange rate as they did in the previous period, which is ruled out by the condition on the learning process in (9). Also, $\mu$ does not equal zero by definition in (16). Second, $(\kappa+\omega)=0$ only if $\kappa=-\omega$, which is nonsense as it implies that the exchange rate would drive foreign exchange demand and supply to the same direction, and it is also ruled out by the conditions in (17) and (18). Third, since $\pi, \delta, \sigma$, and $\lambda$ are all positive, the expression in the third bracket is 
positive as well. Moreover, fourth, the last expression is also positive as all the parameters in the denominator are positive. Thus, the determinant fulfils the stability criteria without any further restrictions on the parameters.

To verify the second condition in (33), the coefficient matrix and its characteristic polynomial have to be calculated:

$$
\begin{gathered}
\operatorname{det}|A-\tau I|=\operatorname{det}\left[\begin{array}{ccc}
\beta-\tau & (1-\beta) & 0 \\
0 & \frac{1}{1+\mu(\kappa+\omega)}-\tau & 0 \\
0 & \mu \delta & 1-\pi \delta-\frac{\sigma}{\lambda}-\tau
\end{array}\right] \\
K(\tau)=(\beta-\tau)\left(\frac{1}{1+\mu(\kappa+\omega)}-\tau\right)\left(1-\pi \delta-\frac{\sigma}{\lambda}-\tau\right)
\end{gathered}
$$

The eigenvalues are the roots of the characteristic polynomial:

$$
\begin{gathered}
\tau_{1}=\beta \\
\tau_{2}=\frac{1}{1+\mu(\kappa+\omega)} \\
\tau_{3}=1-\pi \delta-\frac{\sigma}{\lambda}
\end{gathered}
$$

The first eigenvalue meets the stability criteria by definition in (9). The second eigenvalue is also smaller than 1 because the value of the denominator is always bigger than 1 . The third one meets the criteria as well since all the parameters are positive and smaller than 1. Consequently, the steady-state described in (32) is stable. In case of any exogenous shock, disturbances are temporary, and the system eventually moves back to the equilibrium. For any known vector of initial conditions, the expected and the actual exchange rate might be calculated for all periods. Let us have the initial conditions as

$$
\overline{G_{0}}=\left[\begin{array}{c}
e_{0}^{e x p} \\
e_{0} \\
p_{0}
\end{array}\right]
$$

At any period, the vector of the expected exchange rate, the actual exchange rate, and the domestic price level is expressed as

$$
\begin{aligned}
& \overline{G_{t}}=\left[\begin{array}{ccc}
\beta & (1-\beta) & 0 \\
0 & \frac{1}{1+\mu(\kappa+\omega)} & 0 \\
0 & \mu \delta & 1-\pi \delta-\frac{\sigma}{\lambda}
\end{array}\right]^{t} \\
& \left(\left[\begin{array}{c}
e_{0}^{e x p} \\
e_{0} \\
p_{0}
\end{array}\right]\left[\begin{array}{c}
\frac{\left[\zeta\left(y_{t-1}+\vartheta\right)-\xi y^{*}\right]}{\mu(\kappa+\omega)} \\
\frac{\left[\zeta\left(y_{t-1}+\vartheta\right)-\xi y^{*}\right]}{\mu(\kappa+\omega)} \\
\left.\frac{\left[\zeta\left(y_{t-1}+\vartheta\right)-\xi y^{*}\right] \pi \delta}{(\kappa+\omega)\left(\pi \delta+\frac{\sigma}{\lambda}\right)}+\left[\left(\gamma-1-\frac{\varphi}{\lambda}\right) y_{t-1}+\frac{\sigma}{\lambda} m_{t-1}+\pi u\right] \frac{1}{\left(\pi \delta+\frac{\sigma}{\lambda}\right)}\right]
\end{array}\right)\right. \\
& +\left[\begin{array}{c}
\frac{\left[\zeta\left(y_{t-1}+\vartheta\right)-\xi y^{*}\right]}{\mu(\kappa+\omega)} \\
\frac{\left[\zeta\left(y_{t-1}+\vartheta\right)-\xi y^{*}\right]}{\mu(\kappa+\omega)} \\
\frac{\left[\zeta\left(y_{t-1}+\vartheta\right)-\xi y^{*}\right] \pi \delta}{(\kappa+\omega)\left(\pi \delta+\frac{\sigma}{\lambda}\right)}+\left[\left(\gamma-1-\frac{\varphi}{\lambda}\right) y_{t-1}+\frac{\sigma}{\lambda} m_{t-1}+\pi u\right] \frac{1}{\left(\pi \delta+\frac{\sigma}{\lambda}\right)}
\end{array}\right]
\end{aligned}
$$


The time-dependent component of (41) determines the dynamics of the system; that is, the characteristics of convergence are set by the parameters in the first bracket. As an equivalent of the stability criteria in equation (33), under any given initial conditions the model converges to the long-term equilibrium since

$$
\lim _{t \rightarrow \infty}\left[\begin{array}{ccc}
\beta & (1-\beta) & 0 \\
0 & \frac{1}{1+\mu(\kappa+\omega)} & 0 \\
0 & \mu \delta & 1-\pi \delta-\frac{\sigma}{\lambda}
\end{array}\right]^{t}=0
$$

Main conclusions from our model are summarized as: $(i)$ the long-term equilibrium exchange rate is independent of the expectations, (ii) the learning process is perfect, as in the steady-state the expected exchange rate equals the spot market rate and (iii) exogenous shocks only cause short-term disturbances. In the next two sections, we introduce political statements as external shocks, and then we integrate them into the learning process to investigate their impact on the exchange rate.

\section{Exogenous Announcements}

As discussed in the first section, political statements affect the exchange rate by altering the expectations of the economic actors. We associate negative news with lower political trust that distracts investors from the assets of the given country and causes the depreciation of its currency. Moreover, the effects are more potent as news spread quicker and gain more publicity than ever before. Bond et al. (2012) found that messages on social networks affect online behavior patterns and change the opinion of the agents about specific topics. Bollen et al. (2011) investigated the impact of individual, political, and economic events on actors using data from their Twitter accounts. They reported a significant correlation between these events and various measures of social mood. Furthermore, the mood spreads through the networks and influences the actions of individuals who are not directly affected by the event's itself (Gil de Zúñiga et al., 2012). In our model, we implement news as political statements sorted in three categories: $(i)$ in case of a neutral statement, the expected exchange rate is described by equation (9), (ii) negative statements shift expectations towards depreciation, and (iii) positive statements shift expectations towards appreciation. The news is exogenous as they are not involved in the learning process.

Consider the non-logarithmic formula for equation (9):

$$
\frac{E_{t}^{e x p}}{E_{t-1}}=\left(\frac{E_{t-1}^{e x p}}{E_{t-1}}\right)^{S}
$$

where $\ln (S)=\beta$. To adopt political statements, we introduce a multiplier factor:

$$
\frac{E_{t}^{\exp }}{E_{t-1}}=\left[\left(\frac{E_{t-1}^{\exp }}{E_{t-1}}\right)^{S}\right] J
$$

where $J$ represents the weight or the potential of the statement as a random variable. The expected value is $J=1$, where $\ln (J)=0$. That is, the expectations and decisions of economic actors are not affected by the news. If $J<1$ than $\ln (J)<0$ and expectations shift towards appreciation. This translates as good news. If $J>1$ than $\ln (J)>0$ and expectations shift towards depreciation. This case corresponds with bad news. The modified 
logarithmic expression for the expected exchange rate at period $t$ is

$$
e_{t}^{e x p}=\beta e_{t-1}^{e x p}+(1-\beta) e_{t-1}+\rho, \text { where } \rho=\ln (J) .
$$

Except for equation (23), the basic model described in (21-26) is unchanged. After the implementation of political statements, the matrix-form is as follows:

$$
\begin{aligned}
{\left[\begin{array}{c}
e_{t}^{e x p} \\
e_{t} \\
p_{t}
\end{array}\right]=} & {\left[\begin{array}{ccc}
\beta & (1-\beta) & 0 \\
0 & \frac{1}{1+\mu(\kappa+\omega)} & 0 \\
0 & \mu \delta & 1-\pi \delta-\frac{\sigma}{\lambda}
\end{array}\right]\left[\begin{array}{c}
e_{t-1}^{e x p} \\
e_{t-1} \\
p_{t-1}
\end{array}\right]+} \\
& {\left[\begin{array}{c}
\rho \\
\frac{\mu}{1+\mu(\kappa+\omega)}\left[\zeta\left(y_{t-1}+\vartheta\right)-\xi y^{*}\right] \\
\left(\gamma-1-\frac{\varphi}{\lambda}\right) y_{t-1}+\frac{\sigma}{\lambda} m_{t-1}+\pi u
\end{array}\right] }
\end{aligned}
$$

For the steady-state, we have:

$$
\overline{\mathcal{E}}=\left[\begin{array}{c}
\frac{\rho}{1-\beta}+\frac{\left[\zeta\left(y_{t-1}+\vartheta\right)-\xi y^{*}\right]}{\mu(\kappa+\omega)} \\
\frac{\left[\zeta\left(y_{t-1}+\vartheta\right)-\xi y^{*}\right]}{\mu(\kappa+\omega)} \\
\frac{\left[\zeta\left(y_{t-1}+\vartheta\right)-\xi y^{*}\right] \pi \delta}{(\kappa+\omega)\left(\pi \delta+\frac{\sigma}{\lambda}\right)}+\left[\left(\gamma-1-\frac{\varphi}{\lambda}\right) y_{t-1}+\frac{\sigma}{\lambda} m_{t-1}+\pi u\right] \frac{1}{\left(\pi \delta+\frac{\sigma}{\lambda}\right)}
\end{array}\right]
$$

Although the long-run equilibrium exchange rate is the same as before, the expectations are affected by the statement, and they differ from the spot market rate for any case when $J \neq 1$. To describe the effects, consider the shift parameter

$$
\frac{\rho}{1-\beta}
$$

By the definition of $\beta$, the denominator is always positive. In the case of bad news, $\rho$ is positive and economic actors expect a higher exchange rate, or in other words, the depreciation of the domestic currency. In the case of good news, $\rho$ is negative, and actors expect a lower exchange rate, that is, the appreciation of the currency. In accordance with the original Dornbusch model, we have an overshooting effect on the short run. The fundamentals of the long-term equilibrium remain unchanged, but non-neutral political statements cause systematic short-term turbulences. Due to the aforementioned social channels, both the frequency and the potential of news and statements are growing, which might cause persistent disturbances. Please note that the amplitude of the overshoot depends on the learning parameter; the less adaptive the economic actors are, the bigger grow the disturbances. However, as long as statements do not affect the output directly, the exchange rate tends towards the original long-term equilibrium.

\section{Integrated Announcements}

In the previous section, political announcements were adapted as exogenous factors. Now we integrate news into the learning process by introducing an additive factor to equation (9). Let us denote the effects of announcements with $\hat{\rho}$, defined as follows; $\hat{\rho}=0$ in case of a neutral statement, $\hat{\rho}<0$ in case of good news, and $\hat{\rho}>0$ in case of bad news. For the expected exchange rate, now we have 


$$
e_{t}^{e x p}=e_{t-1}^{e x p}+(\beta+\hat{\rho})\left(e_{t-1}-e_{t-1}^{e x p}\right)
$$

Positive statements drive actors to assign less weight on correcting their mistakes during the learning process, while negative statements raise awareness and foster adaptive learning. After solving the model, we found that statements do not change the original long-run equilibrium described in equation (32). However, the stability is affected. Consider the coefficient-matrix and the characteristic polynomial of the new system:

$$
\begin{gathered}
\operatorname{det}|A-\tau I|=\operatorname{det}\left[\begin{array}{ccc}
\beta+\hat{\rho}-\tau & 1-(\beta+\hat{\rho}) & 0 \\
0 & \frac{1}{1+\mu(\kappa+\omega)}-\tau & 0 \\
0 & \mu \delta & 1-\pi \delta-\frac{\sigma}{\lambda}-\tau
\end{array}\right] \\
K(\tau)=(\beta+\hat{\rho}-\tau)\left(\frac{1}{1+\mu(\kappa+\omega)}-\tau\right)\left(1-\pi \delta-\frac{\sigma}{\lambda}-\tau\right)
\end{gathered}
$$

The eigenvalues are

$$
\begin{gathered}
\tau_{1}=\beta+\hat{\rho} \\
\tau_{2}=\frac{1}{1+\mu(\kappa+\omega)} \\
\tau_{3}=1-\pi \delta-\frac{\sigma}{\lambda}
\end{gathered}
$$

Again, the equilibrium solution is only stable if the absolute values of the eigenvalues are less than one. Roots (53) and (54) are identical to (38) and (39) from the basic model, but now (52) does not meet the stability criteria. The system turns unstable if the announcements are very potent, that is, the absolute value $\hat{\rho}$ of is relatively big. In case of seriously bad news or political distrust, a strong negative overshooting effect causes instability, while very intense good news creates foreign exchange bubbles. Consequently, the disorder might be persistent.

\section{Cases of Hungary}

On the 3rd of June 2010, the vice-president of the new Hungarian government made a negative announcement about the national budget and referred to a possible sovereign default. The statement reflected his political opinion, and there were no new economic indicators or other fundamental information released. However, the exchange rate of the Hungarian Forint against the Euro went from around 275 to almost 288 in just a couple of days. As shown in Figure 1, after a significant negative overshoot, the exchange rate converged back towards the equilibrium level. The outcome corresponds with the shortterm turbulence in our model.

Our other case relates to the so-called Sargentini-report. Officially accepted by the European Parliament Committee on Civil Liberties, Justice and Home Affairs on the 25th of June 2018, the report concluded that the fundamental values of the European Union were violated in several aspects in Hungary. This translates to a lack of political trust on the European level, which might distract investors from assets denominated in Hungarian Forints. Although the main statements were published, and even discussed before, just 


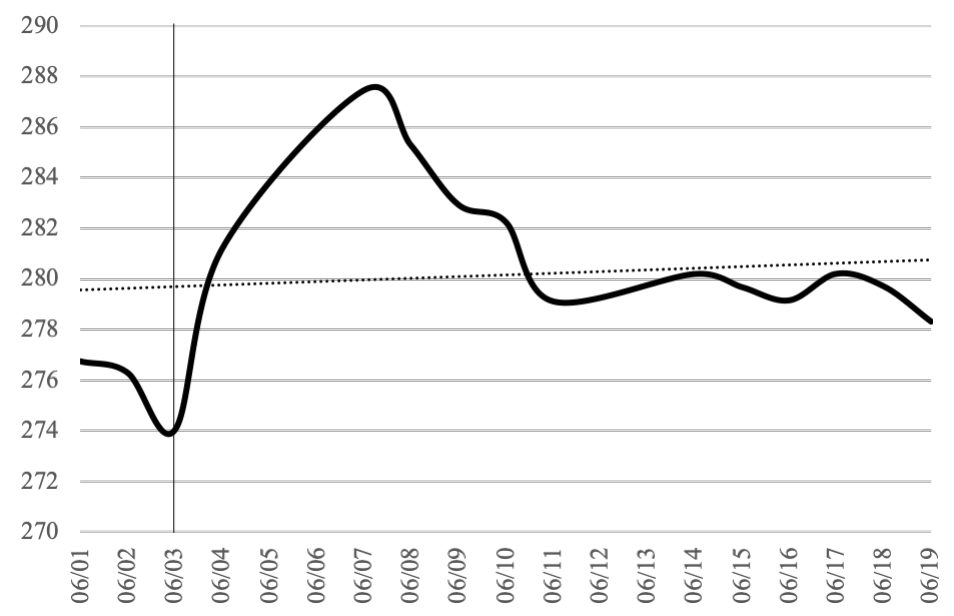

Figure 1: HUF / Euro exchange rate in June 2010

by the change in its legal status, the report caused a significant negative overshoot in the foreign exchange market. Let us point out that news on economic fundamentals was not involved and the report was a political statement, not an economic evaluation. Still, the exchange rate went from around 325 to 330 in the following days and then returned to its previous level. Figure 2 shows that after reaching its peak on the 2nd of July, the exchange rate converges back to the equilibrium.

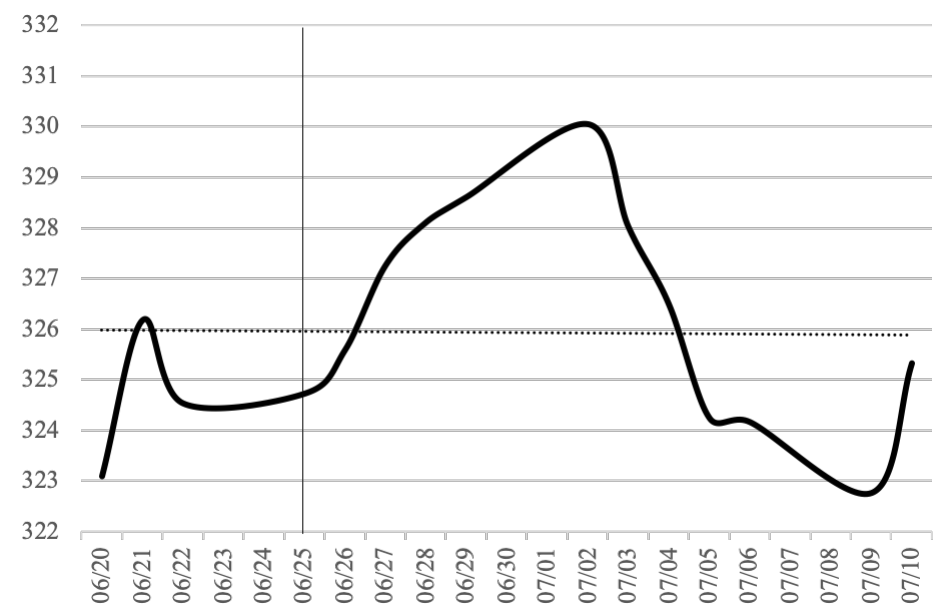

Figure 2: HUF / Euro exchange rate in summer 2018

In both cases, the turbulences are consistent with our model as they only affect the exchange rate on the short-run. Bad news triggered an overshooting mechanism usually lasting for a few days, but eventually, the system evolves towards the long-run equilibrium. Due to adaptive learning, actors were able to correct their expectations remarkably quick. 


\section{Concluding Remarks}

We presented a dynamic model of a small open economy to investigate the effects of political announcements on the currency exchange rate. To develop our concept, we adopted the Dornbusch model to discrete variables and extended the framework with adaptive expectations. After calculating the steady-state solution for the basic model, we introduced political announcements as exogenous factors, and then we integrated them into the learning process.

Our results show that $(i)$ in the long-run equilibrium the expected exchange rate equals the spot market rate, $(i i)$ the steady-state of the system is stable, (iii) political announcements do not affect the equilibrium exchange rate but induce short-term disturbances, and (iv) negative announcements cause a temporary depreciation while positive announcements cause a temporary appreciation of the currency. The conclusions are also supported by two short case-studies from Hungary.

Some announcements might cause persistent disorder if their effects get anticipated in the learning process. Potent news induces such a strong overshooting that the steady-state turns unstable and long-lasting disturbances arise. However, we consider instability as a special case since it requires a very specific configuration of learning parameters.

\section{Appendix}

\begin{tabular}{cl}
\hline Parameter $(\log )$ & Description (range) \\
\hline$E_{t}\left(e_{t}\right)$ & Exchange rate in period t \\
$E_{t}^{e x p}\left(e_{t}^{e x p}\right)$ & Expected exchange rate in period t \\
$P_{t}\left(p_{t}\right)$ & Domestic price level in period t \\
$Y_{t}\left(y_{t}\right)$ & Domestic national income in period t \\
$Y_{t}^{*}\left(y_{t}^{*}\right)$ & Foreign national income in period t \\
$M_{t}\left(m_{t}\right)$ & Domestic money supply in period t \\
$R_{t}\left(r_{t}\right)$ & Domestic interest rate in period t \\
$R_{t}^{*}\left(r_{t}^{*}\right)$ & Global interest rate in period t \\
$\Psi(\varphi)$ & Change in the global interest rate $\Psi \in(-1,1)$ \\
$T(\tau)$ & Change in the domestic money supply $T \in(-1,1)$ \\
$H(\vartheta)$ & Change in the domestic national income $H \in(-1,1)$ \\
$x_{t}$ & Appreciation / depreciation of the domestic currency in period t \\
$\beta$ & Learning parameter for adaptive expectations $\beta \in(0,1)$ \\
$\phi$ and $\lambda$ & Parameters of the Cagan-type money demand function $\lambda \in(0,1)$ \\
$\pi$ & Speed of adjustment from the original Dornbusch model \\
$u$ & Shift parameter from the original Dornbusch model \\
$\delta$ & Difference parameter from the original Dornbusch model \\
$\gamma$ & Income multiplier from the original Dornbusch model \\
$\mu$ & Weight parameter from the original Dornbusch model \\
$\sigma$ & Interest rate parameter from the original Dornbusch model \\
$D_{t}^{D}$ and $D_{t}^{S}$ & Demand and supply of foreign currency in period t \\
$\kappa$ and $\zeta$ & Parameters of the demand for foreign currency \\
$\omega$ and $\xi$ & Parameters of the supply of foreign currency \\
$J(\rho)$ & The "weight" or the "potential" of political announcements \\
$\hat{\rho}$ & The "quality" of the announcement (negative, positive, or neutral) \\
\hline
\end{tabular}




\section{References}

Bachman, D. (1992). The Effect of Political Risk on the Forward Exchange Bias: The Case of Elections. Journal of International Money and Finance, 11(2), 208-19. doi:10.1016/02615606(92)90042-V

Blomberg, S. B., \& Hess, G. D. (1997). Politics and Exchange Rate Forecasts. Journal of International Economics, 43(1-2), 189-205. doi:10.1016/S0022-1996(96)01466-3

Bollen, J., Mao, H., \& Pepe, A. (2011). Modeling Public Mood and Emotion: Twitter Sentiment and Socio-Economic Phenomena. In The Fifth International AAAI Conference on Weblogs and Social Media (p. 450-53). https://www. aaai.org/ocs/index.php/ICWSM/ ICWSM11/paper/viewFile/2826/3237.

Bond, R. M., Fariss, C. J., Jones, J. J., Kramer, A. D. I., Marlow, C., Settle, J. E., \& Fowler, J. H. (2012). A 61-million-person Experiment in Social Influence and Political Mobilization. Nature, 489(7415), 295-98. doi:10.1038/nature11421

Cosset, J.-C., \& de la Rianderie, B. D. (1985). Political Risk and Foreign Exchange Rates: An Efficient-markets Approach. Journal of International Business Studies, 16(3), 21-55. doi:10.1057/palgrave.jibs. 8490458

Dornbusch, R. (1976). Expectations and Exchange Rate Dynamics. Journal of Political Economy, 84 (6), 1161-76. doi:10.1086/260506

Frenkel, J. A. (1982). Flexible Exchange Rates, Prices and the Role of "News": Lessons from the 1970s. In R. A. Batchelor \& G. E. Wood (Eds.), Exchange Rate Policy (pp. 48-92). London: Palgrave Macmillan UK. doi:10.1007/978-1-349-16863-7

Galor, O. (2004). Introduction to Stability Analysis of Discrete Dynamical Systems (Tech. Rep. No. 0409011). University Library of Munich, Germany. https://ideas.repec.org/ p/wpa/wuwpma/0409011.html.

Galor, O. (2005). Discrete Dynamical Systems (Tech. Rep.). University Library of Munich, Germany. https://EconPapers.repec.org/RePEc: wpa: wuwpge:0504001.

Gil de Zúñiga, H., Jung, N., \& Valenzuela, S. (2012). Social Media Use for News and Individuals' Social Capital, Civic Engagement and Political Participation. Journal of ComputerMediated Communication, 17(3), 319-36. doi:10.1111/j.1083-6101.2012.01574.x

Hetherington, M. J. (1998). The Political Relevance of Political Trust. American Political Science Review, 92(4), 791-808. doi:10.2307/2586304

Kaiser, U. (1997). The Impact of Political Announcements on Expectations Concerning the Starting Date of the EMU (Discussion Papers No. 97-31). ZEW.

Mundell, R. A. (1963). Capital Mobility and Stabilization under Fixed and Flexible Exchange Rates: A Comment. The Canadian Journal of Economics and Political Science, 29(4), 475-85. doi:10.2307/139707 
Mussa, M. (1976). The Exchange Rate, the Balance of Payments and Monetary and Fiscal Policy under a Regime of Controlled Floating. Scandinavian Journal of Economics, 78(2), 229-48. doi:10.2307/3439926

Niederhoffer, V. (1971). The Analysis of World Events and Stock Prices. The Journal of Business, 44 (2), 193-219. doi:10.1086/295352

Samuelson, P. A. (1964). Theoretical Notes on Trade Problems. The Review of Economics and Statistics, 46(2), 145-54. doi:10.2307/1928178

Sohu, J. M., Junejo, I., \& Hussain, F. (2019). The Impact of Corruption on Exchange Rate: Empirical Evidence from Panel Data. Sukkur IBA Journal of Management and Business, 6(1). doi:10.30537/sijmb.v6i1.264 